\title{
Relative contributions of different food groups to vitamin $D$ intake in Asian and Caucasian UK women: results from the Vitamin D, Food Intake, Nutrition and Exposure to Sunlight in Southern England (D-FINES) Study
}

\author{
A. L. Darling, P. A. Lee, L. Tan, K. Sui, K. H. Hart and S. A. Lanham-New \\ Nutritional Sciences Division, Faculty of Health and Medical Sciences, University of Surrey, Guildford GU2 7HX, UK
}

There has been a lack of research into the contribution of different food groups to vitamin D intake in varying age and ethnic groups in the UK. The 2006-7 D-FINES Study was undertaken in 373 Surrey premenopausal (PRM) and post-menopausal (POM) Caucasian (C) and Asian (A) women. They were assessed in four seasons of the year for vitamin D (25OHD) status, vitamin D dietary intake and UVB exposure. Relative contributions from different food groups for vitamin D intake were calculated for A and C women in each of the four seasons.

As can be seen in the Table, the top three sources of vitamin D in Asians were meat, cereals and eggs. In Caucasians the top sources were meat, fish and cereals. Analysis by ANOVA indicated that A women obtained a significantly higher percentage of vitamin D from eggs and egg products, meat products and from vegetable foods than the $\mathrm{C}$ women. However, $\mathrm{C}$ women had a significantly higher absolute vitamin D intake $(P<0.001)$. When the women were divided into four groups by ethnicity and menopausal status, significant differences were found in vitamin D intake from cereals, egg products, vegetables and snacks between the groups but no differences were found for milk, fish, meat and fats. These differences were found to be to be significant (post hoc tests) only between the PRM A and POM C groups. For absolute intakes, there was a significant difference between the four groups $(P<0.001)$. POM C had the highest intake (post hoc tests), followed in order by PRM C, PRM A and POM A, although significant differences were only found between intakes of POM A and POM C $(P<0.001)$, and between POM A and PRM C $(P=0.026)$.

Table. Percentage vitamin D intake obtained from different food groups

\begin{tabular}{|c|c|c|c|c|c|c|c|c|c|c|c|c|c|c|}
\hline \multirow[b]{3}{*}{ Vitamin D (\%) from: } & \multirow{2}{*}{\multicolumn{2}{|c|}{$\begin{array}{r}\text { All C } \\
n 279 \\
\end{array}$}} & \multirow{2}{*}{\multicolumn{2}{|c|}{$\begin{array}{c}\text { All A } \\
n 94\end{array}$}} & \multirow[b]{3}{*}{$P$} & \multirow{2}{*}{\multicolumn{2}{|c|}{$\frac{\text { POM C }}{n 144}$}} & \multirow{2}{*}{\multicolumn{2}{|c|}{$\begin{array}{c}\text { PRM C } \\
n 135\end{array}$}} & \multirow{2}{*}{\multicolumn{2}{|c|}{$\frac{\text { POM A }}{n 44}$}} & \multirow{2}{*}{\multicolumn{2}{|c|}{$\frac{\text { PRM A }}{n 50}$}} & \multirow[b]{3}{*}{$P$} \\
\hline & & & & & & & & & & & & & & \\
\hline & Mean & SD & Mean & SD & & Mean & SD & Mean & SD & Mean & $\mathrm{SD}$ & Mean & SD & \\
\hline Cereals & 20.0 & 23.9 & 24.5 & 24.2 & 0.31 & 16.5 & 20.4 & 24.3 & 27.1 & 19.6 & 26.5 & 30.9 & 19.6 & 0.04 \\
\hline Milk and milk products & 12.3 & 16.4 & 13.3 & 19.0 & 0.39 & 11.8 & 13.6 & 12.9 & 19.3 & 15.7 & 22.9 & 10.1 & 12.2 & 0.27 \\
\hline Eggs & 10.7 & 16.2 & 14.8 & 22.2 & 0.04 & 11.9 & 16.3 & 9.3 & 16.1 & 19.1 & 26.0 & 9.2 & 15.1 & 0.03 \\
\hline Vegetables & 1.9 & 6.7 & 2.3 & 7.3 & 0.02 & 1.20 & 3.6 & 2.7 & 9.1 & 2.7 & 9.3 & 1.8 & 3.3 & 0.03 \\
\hline Fish & 24.9 & 32.4 & 13.4 & 25.6 & 0.30 & 28.8 & 33.4 & 20.0 & 30.6 & 12.3 & 25.7 & 14.8 & 25.8 & 0.42 \\
\hline Meat & 25.3 & 23.5 & 28.3 & 19.8 & 0.02 & 25.1 & 22.4 & 25.4 & 25.0 & 19.4 & 20.1 & 30.5 & 19.5 & 0.09 \\
\hline Fats and oils & 3.1 & 10.0 & 1.8 & 7.1 & 0.71 & 2.7 & 8.4 & 3.57 & 11.7 & 1.3 & 4.0 & 2.5 & 9.8 & 0.45 \\
\hline Snacks & 0.5 & 3.4 & 1.6 & 9.8 & 0.14 & 0.3 & 1.4 & 0.75 & 4.8 & 2.6 & 13.1 & 0.3 & 0.9 & 0.03 \\
\hline Other & 0.3 & 0.9 & - & - & - & 0.3 & 0.8 & 0.27 & 1.1 & - & - & - & - & 0.06 \\
\hline Absolute intake $(\mu \mathrm{g})$ & 2.7 & 2.3 & 1.7 & 1.3 & $* * *$ & 2.9 & 2.5 & 2.4 & 2.0 & 1.4 & 1.1 & 2.0 & 1.5 & $* * *$ \\
\hline
\end{tabular}

$* * * P<0.001$.

A women had lower intakes of vitamin D than $\mathrm{C}$ women, which is of concern as $\mathrm{C}$ intakes are already low at $2.8 \mu \mathrm{g} / \mathrm{d}(1)$. There are clear ethnic differences in the amount of vitamin D obtained from different food groups, with groups such as eggs, vegetables and meat being more important sources for A than $\mathrm{C}$. This result has important implications for public health campaigns for increasing vitamin $\mathrm{D}$ intake in UK populations and for tailoring dietary advice to the individual.

This work was funded by the Food Standard Agency (Project N05064). The kind help with subject recruitment given by the Islamic Resource Centre Kingston, Woking Khidmat Group, Woking Asian Women's Association, Thornton Health Asian Association and College Road Surgery, Woking is gratefully acknowledged.

1. Hoare J, Henderson L, Bates CJ, Prentice A, Birch M, Swan G, Farron M. (2004) The National Diet \& Nutrition Survey: adults aged 19 to 64 years: Summary Report. London: TSO. 